\title{
Methods for Determination of $\mathrm{Fe}^{3+} / \sum \mathrm{Fe}$ in Microscopic Samples
}

McCammon, C.A.

Bayerisches Geoinstitut, Universität Bayreuth, D-95440 Bayreuth, Germany

\section{Introduction}

Analytical methods have evolved such that determination of chemical composition in microscopic samples can be carried out with high precision and spatial resolution. However, none of the analytical methods are able to distinguish between different valence states, e.g. $\mathrm{Fe}^{2+}$ and $\mathrm{Fe}^{3+}$, which is crucial to determination of important parameters such as oxygen fugacity. Methods such as wet chemistry can be used to measure $\mathrm{Fe}^{3+} / \Sigma \mathrm{Fe}$ values, but cannot be applied to small samples. To address this problem, methods have been evolving in recent years to measure $\mathrm{Fe}^{3+} / \Sigma \mathrm{Fe}$ with higher spatial resolution. This paper will critically examine these methods and describe some recent applications.

\section{Electron microprobe}

The possiblity to calculate the stoichiometric formula of a mineral from its chemical analysis is often applied to determine $\mathrm{Fe}^{3+} / \Sigma \mathrm{Fe}$ values from electron microprobe analyses. It is important, however, to propagate the uncertainties through the calculation in order to evaluate the significance of the results. For example, Canil and O'Neill (1996) calculate uncertainties in $\mathrm{Fe}^{3+} / \sum \mathrm{Fe}$ for representative mantle samples of spinel, garnet and clinopyroxene to be $2.5 \%, 12 \%$ and $51 \%$, respectively. Additional errors are introduced if the phase is not stoichiometric, or if there are other cations present with multiple valence.

Another possibility to determine $\mathrm{Fe}^{3+} / \Sigma \mathrm{Fe}$ using the electron microprobe is through analysis of oxygen (e.g. Bastin and Heijligers, 1989). Sample preparation is critical, however, since emission is restricted to shallow depths (of the order $1000 \AA$ ). Effects such as surface contamination and roughness are disastrous, and it is crucial to use correct procedures in collecting and analysing the data. As above, calculation of $\mathrm{Fe}^{3+} / \sum \mathrm{Fe}$ assumes that phases are stoichiometric and that iron is the only cation with multiple valence.

A more direct method for calculating $\mathrm{Fe}^{3+} / \Sigma \mathrm{Fe}$ using the electron microprobe has been recently developed by Höfer et al. (1994) through analysis of the $\mathrm{Fe}_{\alpha} \mathrm{L}_{\alpha}$ and $\mathrm{L}_{\beta} \mathrm{X}$-ray emission spectra. Calibration curves between $\mathrm{Fe}^{3+} / \Sigma \mathrm{Fe}$ and the intensity ratio $\mathrm{L}_{\beta} / \mathrm{L}_{\alpha}$ are structure dependent, but can be determined with an accuracy of $\pm 5 \%$ in $\mathrm{Fe}^{3+} / \Sigma \mathrm{Fe}$ as shown by Enders et al. (1997) for alkaliandcalcic-amphiboles.

\section{X-ray Photoelectron Spectroscopy (XPS)}

Photoelectron energy spectra obtained by bombarding a sample with X-rays can be analysed to provide information about the elemental and chemical state of the atoms. In particular, $\mathrm{Fe}^{2+}$ and $\mathrm{Fe}^{3+}$ have photopeaks at different energies, so the oxidation state of $\mathrm{Fe}$ can be determined with reasonable accuracy (e.g. McIntyre and Zetaruk, 1977). A recent study by Raeburn et al. (1997a,b) applied the method to biotite samples with a spot size of $2 \times 0.25 \mathrm{~mm}$ and an accuracy of $5-15 \% \mathrm{in} \mathrm{Fe}^{3+} / \Sigma \mathrm{Fe}$. One advantage of the method is the wide availability of XPS instruments, while a large disadvantage is the strong surface sensitvity (typically only the top $5 \mathrm{~nm}$ are sampled). 


\section{X-ray Absorption Near-Edge Spectroscopy (XANES)}

The X-ray $\mathrm{K}$ - and $\mathrm{L}$-absorption edges of iron have features which are sensitive to the valence electrons, and can be used to estimate $\mathrm{Fe}^{3+} / \sum \mathrm{Fe}$. The $\mathrm{L}$ edge is dominated by dipole transitions which are sensitive to oxidation state, site symmetry, spin state and crystal field splitting, and has been used to characterise valence states for a number of different $3 \mathrm{~d}$ transition metals (e.g. Cressey et al., 1993). The pre-edge region of the $\mathrm{K}$-absorption edge is sensitive primarily to oxidation state, and has been used in numerous studies to determine $\mathrm{Fe}^{3+} / \Sigma \mathrm{Fe}$. For example, a recent study by Delaney et al. (1996) determined $\mathrm{Fe}^{3+} / \Sigma \mathrm{Fe}$ values in amphibole with a spot size of $30 \times 50 \mu \mathrm{m}$. Advantages of the method include the potentially high spatial resolution (to $\sim 1 \mu \mathrm{m}$ ), while a disadvantage is the need for a synchrotron source of X-rays.

\section{Electron Energy Loss Spectroscopy (ELNES)}

ELNES is the electron equivalent of XANES. The energy spectrum can be measured using a highresolution spectrometer attached to a standard transmission electron microscope. The energy difference in maxima arising from $\mathrm{Fe}^{2+}$ and $\mathrm{Fe}^{3+}$ in the spectrum is sufficiently large to enable quantitative determination of $\mathrm{Fe}^{2+} / \mathrm{Fe}^{3+}$ ratios. $\mathrm{Fe} \mathrm{L}_{2,3}$ edge spectra were used by van Aken et al. (1998) on a large suite of synthetic and natural minerals to calibrate $\mathrm{Fe}^{3+} / \Sigma \mathrm{Fe}$ values determined by Mössbauer spectroscopy with values determined from the intergal intensity ratio $\mathrm{L}_{3} / \mathrm{L}_{2}$. Absolute errors for the quantitative determination were estimated to be approximately \pm 0.05 for $\mathrm{Fe}^{3+} / \Sigma \mathrm{Fe}<$ 0.4 and \pm 0.03 for $\mathrm{Fe}^{3+} / \Sigma \mathrm{Fe}>0.6$. A large advantage of the method is the extremely high spatial resolution possible (down to $\sim 10 \mathrm{~nm}$ ), while one disadvantage is the destructive nature of sample preparation.

\section{Mössbauer spectroscopy}

Mössbauer spectroscopy is a reliable method for determination of $\mathrm{Fe}^{3+} / \Sigma \mathrm{Fe}$, and provides additional crystal chemical information about the environment of iron in the sample. Traditionally it has required samples with diameter $\sim 1 \mathrm{~cm}$, but a method developed by McCammon et al. (1991) enables experiments to be carried out on samples of diameters as small as $50 \mu \mathrm{m}$ (see also McCammon, 1994). Advantages of the method include the wide availability of Mössbauer spectrometers and the non-destructive nature of the technique, while disadvantages are the limited spatial resolution (not less than $50 \mu \mathrm{m}$ ) and the relatively long time required to collect spectra (>12 hr).

\section{Applications}

Applications of techniques to determine $\mathrm{Fe}^{3+} / \Sigma \mathrm{Fe}$ in microscopic samples are numerous. The Mössbauer method has been applied to a number of mantle problems:

(1) Oxygen fugacity conditions during formation of diamonds from George Creek, Colorado as measured from $\mathrm{Fe}^{3+} / \sum \mathrm{Fe}$ of garnet and clinopyroxene inclusions (McCammon et al., 1998 )

(2) $\mathrm{Fe}^{3+}$ content of inclusions in diamond from the lower mantle with implications for lower mantle oxidation state (McCammon et al., 1997)

(3) Distribution of $\mathrm{Fe}^{3+}$ in garnets from the Wesselton kimberlite with implications for oxygen fugacity (McCammon et al., in preparation) 


\section{References}

Bastin, G. F., and Heijligers, H. J. M., 1989, Quantitative electron probe microanalysis of oxygen: Eindhoven, Netherlands, University of Technology.

Canil, D., and O'Neill, H. S. C., 1996, Distribution of ferric iron in some upper-mantle assemblages: J. Petrol., v. 37, p. 609-635.

Cressey, G., Henderson, C. M. B., and van der Laan, G., 1993, Use of L-edge X-ray absorption spectroscopy to characterise multiple valence states of $3 \mathrm{~d}$ transition metals; a new probe for mineralogical and geochemical research: Physics and Chemistry of Minerals, v. 20, p. 111-119.

Delaney, J. S., Bajt, S., Sutton, S. R., and Dyar, M. D., 1996, In situ microanalysis of $\mathrm{Fe}^{3+} / \sum \mathrm{Fe}$ in amphibole by x-ray absorption near edge strcuture (XANES) spectroscopy, in Dyar, M. D., McCammon, C. A., and Schaeffer, M., eds., Mineral Spectroscopy: A Tribute to Roger G. Burns, 5: USA, Geochemical Society, p. 165-171.

Enders, M., Speer, D., McCammon, C., and Maresch, W., 1997, $\mathrm{Fe}^{2+}-\mathrm{Fe}^{3+}$ ratios in alkaliamphiboles with the electron-microprobe: Terra Nova, v. 9, p. 432.

Höfer, H. E., Brey, G. P., Schulz-Dobrick, B., and Oberhänsli, R., 1994, The determination of the oxidation state of iron by the electron microprobe: Eur. J. Mineral., v. 6, p. 407-418.

McCammon, C. A., 1994, A Mössbauer milliprobe: Practical considerations: Hyper. Inter., v. 92, p. 1235-1239.

McCammon, C. A., Chaskar, V., and Richards, G. G., 1991, A technique for spatially resolved Mössbauer spectroscopy applied to quenched metallurgical slags: Meas. Sci. Technol., v. 2, p. 657-662.

McCammon, C. A., Hutchison, M., and Harris, J., 1997, Ferric iron content of mineral inclusions in diamonds from São Luiz: A view into the lower mantle: Science, v. 278, p. 434-436.

McCammon, C., Chinn, I., Gurney, J., and McCallum, M., 1998, Ferric iron content of mineral inclusions in diamonds from George Creek, Colorado determined using Mössbauer spectroscopy: Implications for oxygen fugacity: Contrib. Mineral. Petrol., in press.

McIntyre, N. S., and Zetaruk, D. G., 1977, X-ray photoelectron spectroscopic studies of iron oxides: Anal. Chem., v. 49, p. 1521-1529.

Raeburn, S. P., Ilton, E. S., and Veblen, D. R., 1997a, Quantitative determination of the oxidation state of iron in biotite using X-ray photoelectron spectroscopy: I. Calibration: Geochim. Cosmochim. Acta, v. 61, p. 4519-4530.

Raeburn, S. P., Ilton, E. S., and Veblen, D. R., 1997b, Quantitative determination of the oxidation state of iron in biotite using X-ray photoelectron spectroscopy: II. In situ analyses: Geochim. Cosmochim. Acta, v. 61, p. 4531-4537.

van Aken, P. A., Liebscher, B., and Styrsa, V. J., Quantitative determination of iron oxidation states in minerals using $\mathrm{Fe} \mathrm{L}_{2,3}$-edge electron energy-loss near-edge structure spectroscopy: Phys. Chem. Minerals, in press. 